\title{
Defining patient outcomes in stage IV colorectal cancer: a prospective study with baseline stratification according to disease resectability status
}

\author{
DJ Watkins', I Chau', D Cunningham,', SS Mudan², N Karanjia ${ }^{3}$, G Brown ${ }^{4}$, S Ashley', AR Norman' and \\ A Gillbanks'
}

'Department of Medicine, Royal Marsden Hospital, London \& Surrey, UK; ²Department of Surgery, Royal Marsden Hospital, London \& Surrey, UK; ${ }^{3}$ Department of Surgery, The Royal Surrey County Hospital, Guildford, UK; ${ }^{4}$ Department of Diagnostic Imaging, Royal Marsden Hospital, London \& Surrey, UK

\begin{abstract}
BACKGROUND: Stage IV colorectal cancer encompasses a broad patient population in which both curative and palliative management strategies may be used. In a phase II study primarily designed to assess the efficacy of capecitabine and oxaliplatin, we were able to prospectively examine the outcomes of patients with stage IV colorectal cancer according to the baseline resectability status.

METHODS: At enrolment, patients were stratified into three subgroups according to the resectability of liver disease and treatment intent: palliative chemotherapy (subgroup A), conversion therapy (subgroup B) or neoadjuvant therapy (subgroup C). All patients received chemotherapy with capecitabine $2000 \mathrm{mg} \mathrm{m}^{-2}$ on days $1-14$ and oxaliplatin $130 \mathrm{mg} \mathrm{m}^{-2}$ on day 1 repeated every 3 weeks. Imaging was repeated every four cycles where feasible liver resection was undertaken after four or eight cycles of chemotherapy.

RESULTS: Of 128 enrolled patients, 74, 22 and 32 were stratified into subgroups A, B and C, respectively. Attempt at curative liver resection was undertaken in 10 (45\%) patients in subgroup B and 19 (59\%) in subgroup C. The median overall survival was I4.6, 24.5 and 52.9 months in subgroups A, B and C, respectively. For patients in subgroups B and C who underwent an attempt at curative resection, 3-year progression-free survival was $10 \%$ in subgroup $B$ and $37 \%$ for subgroup $C$.

CONCLUSIONS: This prospective study shows the wide variation in outcome according to baseline resectability status and highlights the potential clinical value of a modified staging system to distinguish between these patient subgroups.

British Journal of Cancer (2010) 102, 255 -26I. doi:I0.I038/sj.bjc.6605508 www.bjcancer.com

(C) 2010 Cancer Research UK
\end{abstract}

Keywords: Stage IV colorectal cancer; liver metastases; peri-operative chemotherapy; metastectomy; liver resection

The overall survival of patients with advanced colorectal cancer has improved from a median of approximately 14 months achieved with 5-FU/LV alone (Douillard et al, 2000; de Gramont et al, 2000) to more than 19 months with the use of combination and sequential cytotoxic therapies (Goldberg et al, 2004; Tournigand et al, 2004; Souglakos et al, 2006). More recently, targeted therapeutics have shown further incremental gains (Hurwitz et al, 2004; Jonker et al, 2007; Van Cutsem et al, 2007) with the prospect of extending survival beyond 24 months in the advanced disease setting (Grothey et al, 2007). For the majority, treatment remains of palliative benefit, with the possibility of cure restricted only to those patients with disease suitable for surgical resection.

Before the advent of combination chemotherapy, the role of metastectomy was limited to those patients who initially presented with disease amenable to surgical resection. However, the high tumour response rates achieved with modern chemotherapeutics

* Correspondence: Professor D Cunningham, Department of Medicine, Royal Marsden Hospital, Downs Road, Sutton, Surrey SM2 5PT, UK; E-mail: david.cunningham@rmh.nhs.uk

Received 25 August 2009; revised 27 November 2009; accepted 29 November 2009 now enable a further proportion of patients with initially inoperable disease to be converted to an operable status and undergo liver resection with curative intent. Reports published by Bismuth et al (1996) and Adam et al (2004a) have shown the potential long-term survival achievable through the use of downsizing chemotherapy or 'conversion therapy' (Khatri et al, 2007) and liver resection, with 5-year survival rates of 33\% (Adam et al, 2004a).

Published data suggest that the ability to undertake liver resection is a significant determinant of patient outcome in stage IV colorectal cancer. However, this has never been formally examined in a prospective study.

At the time of planning this study, one of the treatment options for patients with inoperable metastatic disease isolated to the liver was infused 5-fluorouracil, leucovorin and oxaliplatin (FOLFOX) (NICE, 2002). The combination of capecitabine and oxaliplatin (CapOx) represented a convenient alternative regimen, with phase II data available to support its use in the advanced disease setting (Borner et al, 2002). During the course of the study, phase III data showing the non-inferiority of CapOx compared with FOLFOX-4 have become available (Cassidy et al, 2008; Rothenberg et al, 2008). The objectives of this study were to further assess the safety and efficacy of capecitabine and oxaliplatin in the palliative disease 
setting and also in the peri-operative setting for patients with potentially resectable liver disease. The study design enabled the prospective evaluation of treatment outcomes according to the baseline disease resectability status and provides a unique data set in this patient population.

\section{METHODS}

This single-arm phase II study recruited patients referred to the Gastrointestinal Cancer Unit at the Royal Marsden Hospital, London and Sutton. The study was approved by the local Ethics Committee and written informed consent was obtained from all patients.

\section{Patients}

Eligible patients diagnosed with advanced colorectal cancer were aged 18 years or older and had not received chemotherapy for advanced disease. Other requirements included unidimensional measurable disease, WHO (World Health Organisation) performance status $0-2$, adequate bone marrow function, adequate liver function (bilirubin $<1.5 \times \mathrm{ULN}$ ), calculated creatinine clearance $>50 \mathrm{mls} \mathrm{min}^{-1}$ and life expectancy of $>12$ weeks. Patients were excluded if they had clinically significant active cardiac disease (congestive cardiac failure, coronary artery disease, cardiac arrhythmia) or myocardial infarction within the last 12 months. Previous adjuvant therapy was allowed, including the administration of oxaliplatin-containing regimens. Patients with significant symptoms of peripheral neuropathy were excluded. Patients with either resectable or non-resectable metastatic disease sites were eligible for study enrolment.

\section{Study design and treatment}

For the purpose of outcome analysis, patients were stratified into one of three subgroups according to their disease resectability status. This was undertaken prospectively by the investigator at the time of study enrolment as outlined in Figure 1. Stratification was based on the considered feasibility of proceeding directly to primary liver resection based on radiological findings, clinical details and multi-disciplinary meeting (MDM) discussion. The aim of stratification was to identify patient subgroups receiving palliative chemotherapy (subgroup A), conversion therapy (subgroup B) or neoadjuvant therapy (subgroup C). Stratification was solely undertaken to allow the outcomes of each patient subgroup to be evaluated independently and had no influence on the care that patients received while participating in the study.

Pre-treatment CT imaging was undertaken within 28 days before commencing study treatment. In addition, patients with liver-only metastases underwent contrast-enhanced MRI imaging of the liver and were discussed in a specialist hepatic MDM. Patients received CapOx chemotherapy consisting of oxaliplatin $130 \mathrm{mg} \mathrm{m}^{-2}$ on day 1 and capecitabine $1000 \mathrm{mg} \mathrm{m}^{-2}$ bd on days $1-14$ repeated every
21 days. Patients aged 75 years or over received a reduced starting dose (oxaliplatin $100 \mathrm{mg} \mathrm{m}^{-2}$ and capecitabine $1500 \mathrm{mg} \mathrm{m}^{-2}$ ). Dose reductions of oxaliplatin were instituted for grade $\geqslant 3$ haematological toxicity (on day of treatment) and grade 3 peripheral neuropathy or grade 2 neuropathy persisting between cycles. Capecitabine dose reductions were instituted for non-haematological capecitabine toxicities of $\geqslant$ grade 2 . Treatment was continued for up to a total of eight cycles. In responding patients, further cycles could be delivered at the discretion of the investigator. CT (and MRI if liver-only metastases) response assessment was undertaken after every four cycles. Patients considered to have potentially resectable disease were re-discussed in the hepatic MDM after every four cycles of treatment. The decision to use surgery or RFA was based on the MDM discussion and was not protocol specified. Liver resection was considered in cases in which macroscopic clearance of disease with clear margins was thought possible, while maintaining adequate residual liver tissue. Surgical resections were planned on the basis of both CT and MRI findings. The preferred timing for liver resection was after four cycles of CapOx chemotherapy, with an interval of 3-6 weeks between the end of chemotherapy and surgery recommended. In cases in which disease remained inoperable, a further four cycles of CapOx could be delivered before re-evaluation. Individual liver lesions that showed a complete response to chemotherapy on liver MRI (and intra-operative ultrasound where undertaken) were not resected. In cases in which resection of both the primary tumour and liver disease was necessary, this could be undertaken as either a combined procedure or sequentially with four cycles of CapOx delivered between each procedure. The use of long-course pre-operative pelvic chemoradiotherapy was permitted in patients with locally advanced rectal tumours. When used, this was administered after an initial four cycles of CapOx chemotherapy. Patients undergoing liver resection after four cycles of CapOx received a further four cycles of post-operative chemotherapy. After the completion of study therapy, patients were followed up on at least a 3-monthly basis.

\section{Statistical analysis}

The primary outcome measure was radiological response rate after four cycles of CapOx chemotherapy. A response rate of $50 \%$ was considered acceptable and a response rate of $35 \%$ unacceptable. Using a minimax design (Simon, 1989) and a one-sided $\alpha$ of 0.05 , a sample size of 117 allowed the exclusion of a radiological response rate of less than $35 \%$ with $95 \%$ power. Planned recruitment was 130 patients to allow for $10 \%$ of patients being non-assessable. Secondary outcome measures included progression-free survival (PFS), overall survival (OS), proportion of patients undergoing liver resection, chemotherapy-related toxicity and 60-day all-cause mortality.

For all patients, progression-free survival was calculated from the date of trial entry until disease progression, post-operative recurrence or death from any cause. Overall survival was

\begin{tabular}{|c||c|c|}
\hline $\begin{array}{c}\text { Subgroup A } \\
\text { Palliative therapy }\end{array}$ & $\begin{array}{c}\text { Subgroup B } \\
\text { Conversion therapy }\end{array}$ & $\begin{array}{c}\text { Subgroup C } \\
\text { Neoadjuvant therapy }\end{array}$ \\
\hline \multirow{2}{*}{$\begin{array}{c}\text { ntage IV disease } \\
\text { not isolated to the } \\
\text { liver }\end{array}$} & $\begin{array}{c}\text { Disease isolated to liver } \\
+/ \text { - primary site. } \\
\text { Primary liver resection } \\
\text { not considered feasible }\end{array}$ & $\begin{array}{c}\text { Disease isolated to liver } \\
+/- \text { primary site. } \\
\text { Primary liver resection } \\
\text { considered feasible }\end{array}$ \\
\hline
\end{tabular}

*Includes those patients with liver involvement and other metastatic disease sites potentially amenable to resection

Figure I Prospective classification according to baseline resectability status. At the time of study entry, enrolled patients were classified into one of three subgroups on the basis of the feasibility of undertaking primary liver resection. 
calculated from the date of trial entry until death from any cause or censored at last follow-up. Both PFS and OS were estimated using the Kaplan-Meier method (Kaplan and Meier, 1958). The objective response rate was assessed by CT according to RECIST criteria (Therasse et al, 2000). Owing to a significant proportion of patients undergoing liver resection after four cycles of CapOx, radiological responses were not confirmed by repeat imaging. Toxicities were evaluated and recorded using the National Cancer Institute Common Toxicity Criteria version 2. A post hoc univariate and step-up multivariate Cox regression analysis was undertaken to examine for prognostic variables in all enrolled patients and in the liver-only subgroups ( $B$ and $C$ ). Factors included in the analysis for all patients were disease site (primary, local, liver, peritoneal, nodal, bone, lung), number of metastatic sites $(1 v s>1)$, subgroup (A $v s \mathrm{~B} v s \mathrm{C})$, age $(<60 v s>60)$, PS ( $2 v s$ 0.1 ), disease-free interval ( $<12 v s>12$ months), synchronous presentation ( $\mathrm{Y} v s \mathrm{~N})$, CEA $(<200 v s>200)$, alk phos $(<300 v s$ $>300)$, $\mathrm{LDH}(<\mathrm{ULN} v s>\mathrm{ULN})$, WCC $(<10$ vs $>10), \mathrm{Hb}(>11$ vs $<11)$ and platelets $(<400 v s>400)$. For the analysis of liver-only patients, largest metastasis $(<5 v s>5 \mathrm{~cm})$ and number of liver metastases $(1 v s>1)$ were also included. PS and Alk phos were excluded in the liver-only group because of low numbers. The data set was locked and analysed in October 2009 with a median followup of 60 months.

\section{RESULTS}

\section{Patient characteristics}

Between September 2002 and April 2006, a total of 128 patients were recruited, with 74, 22 and 32 patients allocated to subgroups $\mathrm{A}, \mathrm{B}$ and $\mathrm{C}$, respectively.

The primary reasons for patients to be considered for conversion therapy (subgroup B $n=22$ ) were large metastasis $(>5 \mathrm{~cm})$ in five patients, multiple metastases $(>4)$ in 12 cases, locally advanced primary in three patients and ill-placed lesions in two patients.

The patient characteristics for each subgroup are shown in Table 1. Patients in subgroup $\mathrm{C}$ were less likely to have presented with synchronous metastatic disease and had a longer interval between primary diagnosis and presentation with metastatic disease. The median number of metastatic liver deposits was lower in subgroup $\mathrm{C}$ compared with subgroup $\mathrm{B}$, with a median of 2 (range $1-5$ ) and 4 (range $1-15$ ), respectively.

\section{Toxicities}

The commonest grade III/IV chemotherapy-related toxicities were diarrhoea, neutropaenia and palmar plantar syndrome (Supplementary Table 2). Oxaliplatin was discontinued early in four patients because of peripheral neuropathy. Four patients discontinued capecitabine because of cardiac chest pain; raltitrexed was substituted for capecitabine in three of these cases. Two patients suffered fatal pulmonary thrombo-embolic events while on treatment. One patient suffered a fatal myocardial infarction and another patient suffered a non-fatal myocardial infarction. One death occurring during the first cycle of therapy was attributable to diarrhoea and dehydration. No deaths were attributable to neutropaenic sepsis, and 60-day all-cause mortality was 3.1\%.

\section{Radiological response and resection rate}

The median number of cycles of chemotherapy delivered was eight. Six patients (4.7\%) were non-evaluable for response. By intention to treat, the overall radiological response rate as assessed by CT was $52.3 \%$ (95\% CI: $43-61 \%$ ); complete response $8.6 \%$, partial response $43.8 \%$, stable disease $30.5 \%$ and progressive disease $12.5 \%$. The radiological response rate and liver resection rate for each subgroup are summarised in Table 2. As would be expected, a higher proportion of patients in subgroup $\mathrm{C}$ underwent an attempt at liver resection than those in subgroup B. Two patients in subgroup A underwent resection of pulmonary metastases and another patient had pulmonary and liver metastases resected. For patients undergoing an attempt at liver resection, the median interval between the end of pre-operative chemotherapy and surgery was 7.6 weeks (range 4-24 weeks).

\section{Liver resections}

A flow diagram indicating the treatment pathways of patients in subgroups $B$ and $C$ is shown in Figure 2. One patient in group B and two patients in group $\mathrm{C}$ achieved a complete response by liver MRI. Liver resection was deferred in these patients. Radiofrequency ablation (RFA) was used in a total of four patients. Two patients in subgroup B received RFA: one in conjunction with surgery and one as an alternative to surgery (liver resection was abandoned as a result of peri-operative bleeding that occurred while resecting the primary during a combined procedure). In subgroup $C$, one patient declined surgical resection and opted for RFA as an alternative. A further patient with significant

Table I Patient characteristics

\begin{tabular}{|c|c|c|c|c|}
\hline & All patients & Subgroup A & Subgroup B & Subgroup C \\
\hline Patient number & 128 & 74 & 22 & 32 \\
\hline Median age (range) & $62(29-78)$ & $61(29-78)$ & $68(38-77)$ & $59(47-76)$ \\
\hline Male (\%) & $77(60)$ & $44(59)$ & $12(52)$ & $21(66)$ \\
\hline PS $2(\%)$ & $10(8)$ & $9(12)$ & I (4) & $0(0)$ \\
\hline Primary in-situ at study entry & & $55 \%$ & $41 \%$ & $28 \%$ \\
\hline Metachronous presentation of $>12$ months & & $27 \%$ & $9 \%$ & $44 \%$ \\
\hline${ }^{a}$ Synchronous presentation & & & $86 \%$ & $53 \%$ \\
\hline Median number of liver deposits (range) & & & $4(1-15)$ & $2(1-5)$ \\
\hline
\end{tabular}

asynchronous presentation defined as the development of metastatic disease within 3 months of primary diagnosis.

Table 2 Patient outcomes

\begin{tabular}{lcccc}
\hline & All patients $\mathbf{n}=\mathbf{I 2 8}$ & Subgroup A $\boldsymbol{n}=\mathbf{7 4}$ & Subgroup B $\boldsymbol{n}=\mathbf{2 2}$ & Subgroup C $\boldsymbol{n}=\mathbf{3 2}$ \\
\hline Median number of cycles (range) & $8(|-| 2)$ & $8(\mid-8)$ & $8(I-\mid 2)$ & $5(2)$ \\
CT response rate CR/PR (\%) & $52 \%$ & $47 \%$ & $5 \%$ & $10(45)$ \\
Attempt at curative resection (\%) & $32(25)$ & $3(4)$ & $59 \%$ & $19(59)$ \\
\hline
\end{tabular}


co-morbidity received RFA as the risk of surgery was felt to be high. A two-stage resection with portal vein embolisation was used in two patients. One patient in subgroup $\mathrm{C}$ had both stages performed successfully. In subgroup B, the patient developed disease progression shortly after the first stage of the planned twostage resection. Macroscopic disease clearance was not achieved in this case. Histopathological examination of resection specimens revealed clear margins in 96\% (eight out of nine in subgroup B and all 19 in subgroup C) of cases. Pathological complete response was found in two cases, one in each of subgroups B and C.

In subgroup $C$, a total of 23 patients (72\%) achieved either liver resection, RFA (with curative intent) or a complete radiological response by MRI. In subgroup $B$, the corresponding figure is 11 patients $(50 \%)$. There were no post-operative deaths related to liver surgery.

\section{Survival}

At a median follow-up of 60 months, $100(78.1 \%)$ patients have died. One patient in subgroup A was not evaluable for PFS as they received second-line irinotecan without documentation of progressive disease. The median overall survival for patients in subgroups A, B and C was 14.6, 24.5 and 52.9 months, respectively. Overall survival and progression-free survival outcomes for the total patient population and for each of the subgroups are shown in Table 3. Supplementary Figure 3 shows the Kaplan-Meier plot for overall survival for all enrolled patients. Overall survival and progression-free survival curves for each patient subgroup are shown in Figure 3.

Of the 29 patients in subgroups $\mathrm{B}$ and $\mathrm{C}$ who underwent an attempt at curative liver resection, six (20.7\%) remain disease free,

Subgroup B

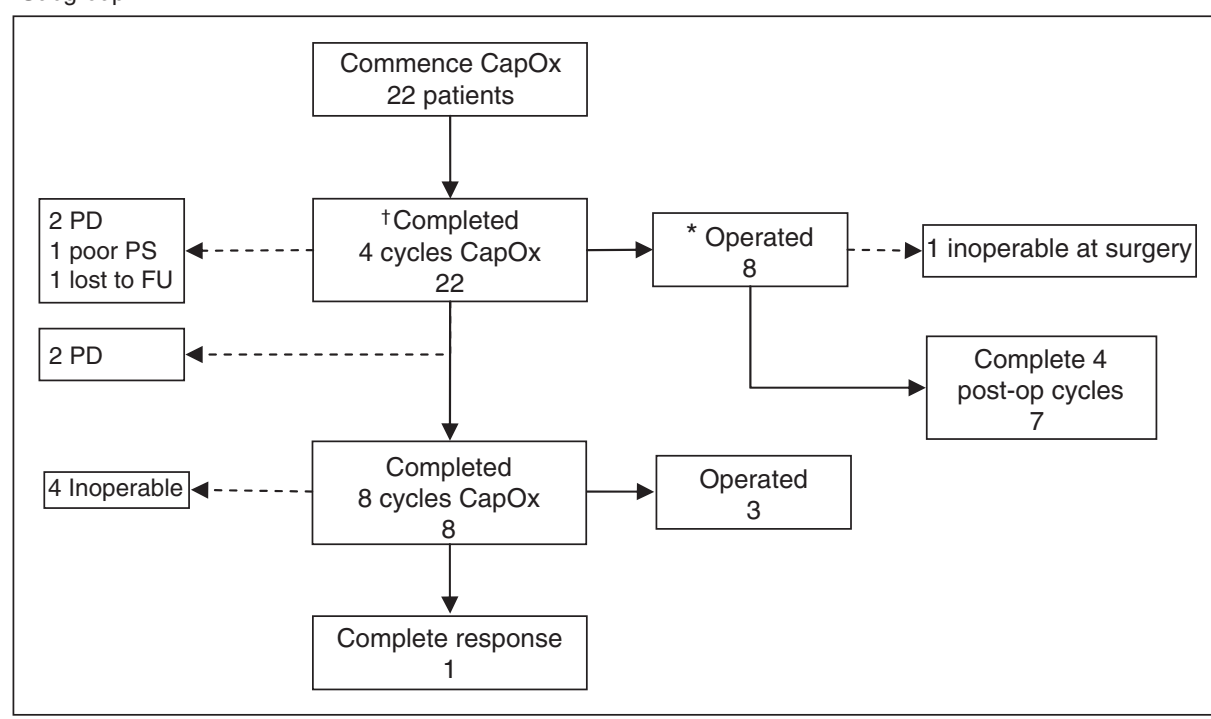

† 1 patient changed from capecitabine to raltitrexed at cycle 2 due to chest pain.

*1 resection abandoned due to peri-operative bleeding, received RFA to solitary metastasis.

Subgroup C

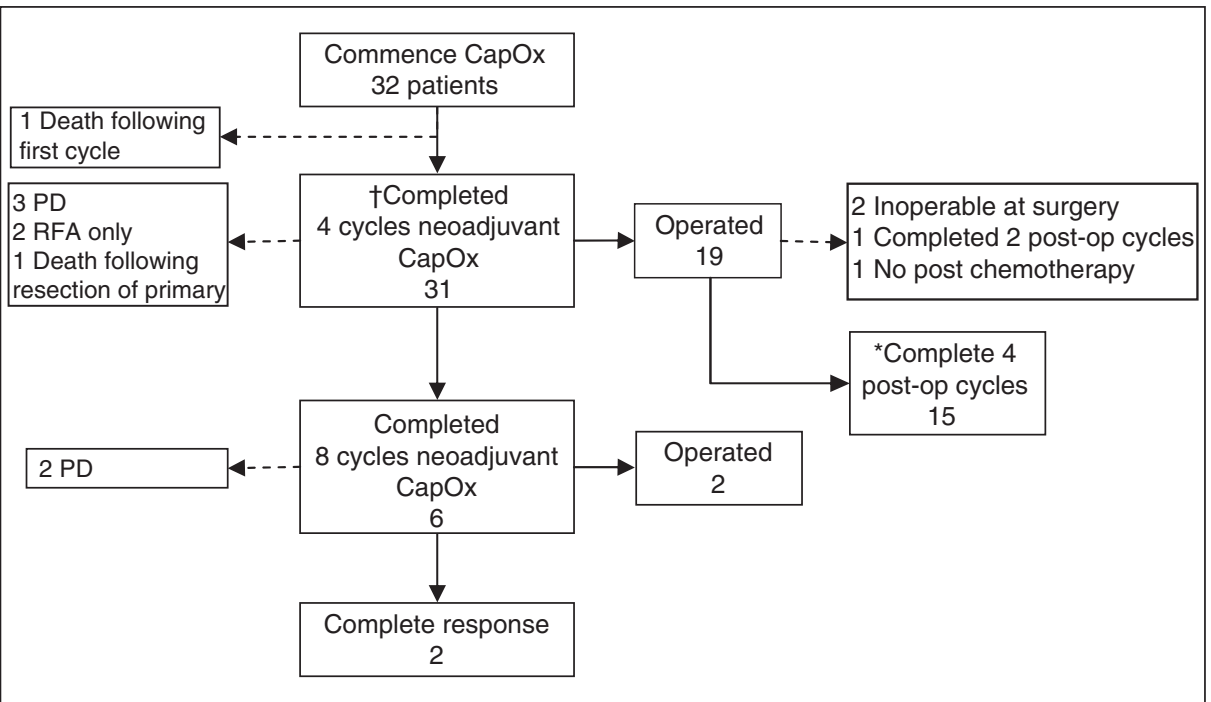

$\dagger 1$ patient changed from capecitabine to raltitrexed at cycle 2 due to chest pain.

*Includes patients who stopped oxaliplatin secondary to neuropathy.

one received capecitabine + mitomycin $\mathrm{C}$.

one capecitabine + irinotecan.

Figure 2 Flow diagram indicating the treatment pathway of patients in subgroups B and C. 
Table 3 Survival outcomes

\begin{tabular}{lcccc}
\hline & All & Subgroup & Subgroup & Subgroup \\
patients & A & B & C \\
\hline Patient number & 128 & 74 & 22 & 32 \\
Median PFS months & 8.7 & 6.9 & 9.7 & 14.7 \\
Median OS months & 20.7 & $\mid 4.6$ & 24.5 & 52.9 \\
3-year OS & $32.4 \%$ & $22.2 \%$ & $23.8 \%$ & $61.5 \%$ \\
(95\% Cl) & $(24-41)$ & $(13-32)$ & $(9-43)$ & $(42-76)$ \\
\hline
\end{tabular}
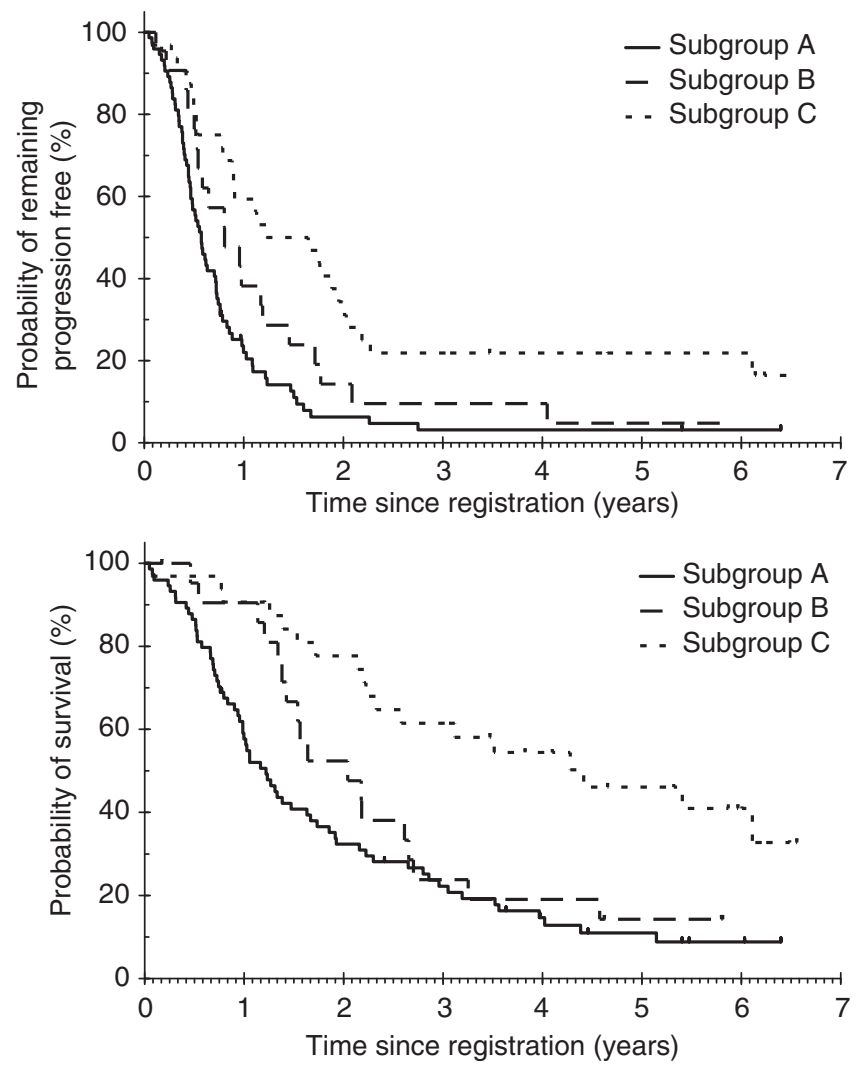

Figure 3 Progression-free survival and overall survival by subgroup.

all from subgroup C. Supplementary Figure 5 shows the progression-free survival and overall survival for subgroup B and $\mathrm{C}$ patients who attempted curative resection. The median PFS for these patients with that attempt resection was 14.0 months in subgroup B and 24.3 months in subgroup C. The corresponding median overall survival was 31.3 months in subgroup B and 73.3 months in subgroup C.

\section{DISCUSSION}

Stage IV colorectal cancer encompasses a heterogeneous patient population in which both palliative and curative treatment strategies may be used. In this prospective study, we stratified patients with stage IV disease into three subgroups according to the feasibility of undertaking curative liver resection. All enrolled patients received treatment according to a protocol-defined strategy, with the planned delivery of eight cycles of CapOx chemotherapy and liver resection considered after four or eight cycles of treatment, where feasible. The comparative outcomes of each subgroup were in keeping with our previous expectations. Subgroup $\mathrm{C}$ had the highest proportion of patients attempting liver resection, with $59 \%$ compared with 45 and $4 \%$ in subgroups B and A, respectively. As would be expected, overall survival was also the longest in subgroup $\mathrm{C}$, with a median of 52.9 months compared with 24.5 and 14.6 months for patients in subgroups B and A, respectively. Examining the outcomes of only those patients who underwent liver resection, we found that patients in subgroup $\mathrm{C}$ continued to fare better than those in subgroup B. Seven (70\%) patients in subgroup B developed progressive or recurrent disease within 12 months of surgery compared with only five $(28.5 \%)$ in subgroup C.

The stratification method adopted in this study was not based on strictly defined criteria. Although this is a potential criticism, we believe that the stratification method used is representative of clinical practice in which factors such as the status of the primary tumour may affect patient management. What is clearly demonstrated by the results of this study is that even within the subgroup of stage IV patients with liver-only metastases (subgroups B and C), marked variation in patient outcome can be seen. The difference in patient outcomes between subgroups B and C can be understood in light of the differing disease characteristics between subgroups (Table 1). Patients in subgroup B had more numerous liver metastases and were also noted to have a shorter median interval from primary diagnosis to the development of metastases. The disparity in disease characteristics between subgroups remained in those patients who underwent an attempt at curative resection (Supplementary Table 5). These characteristics are known adverse risk factors for disease recurrence following hepatic resection (Schlag et al, 1990; Sato et al, 1998; Fong et al, 1999; Iwatsuki et al, 1999; Tsai et al, 2007; Rees et al, 2008) and are likely to account for the inferior outcomes seen in subgroup B. Data reported by Adam et al (2004a) has similarly shown inferior survival outcomes for patients undergoing resection after conversion therapy, compared with those with disease amenable to primary liver resection.

To further examine for potential baseline prognostic factors, an exploratory univariate and multivariate Cox regression analysis was undertaken (Supplementary Tables 6 and 7). For the entire patient cohort, stratification to subgroup C, alk phos $<300$ and absence of peritoneal disease were found to be independently predictive of both PFS and OS. In the liver-only patient subgroup (B and C), no independently significant prognostic factors for PFS were identified. Stratification to subgroup B and age $>60$ years were noted to be independently predictive of shorter overall survival.

In view of the wide variation in survival outcomes seen among patients presenting with stage IV colorectal cancer, modification of the AJCC staging system (Greene et al, 2002) to allow the subcategorization of stage IV patients has been proposed (Nagashima et al, 2006; Poston et al, 2006, 2008; Nordlinger et al, 2007). Currently, there remains no widely accepted method of subclassification; however, our data would lend support to the suggested incorporation of liver resectability status in a revised colorectal cancer-staging system (Nordlinger et al, 2007).

A strength of our study data is that the resectability status of each patient was identified prospectively at study entry, thus avoiding the potential pitfalls associated with retrospective classification. The proportion of enrolled patients with liver only disease was higher than would be expected at $42 \%$. It is likely that funding restrictions that applied to the use of oxaliplatin during the period of the study (NICE, 2002) would have biased enrolment towards patients with liver only disease and may have also resulted in the underrepresentation of patients with operable metastases at other visceral sites. This factor should not have influenced the characteristics or the comparative outcomes of the individual patient subgroups.

At the time of initiating this study, there were no data to support the use of neoadjuvant chemotherapy in patients with resectable liver metastases. The subsequently published results of the EORTC 40983 study now lend support to this approach (Nordlinger et al, 
2008). Although the 40983 study did not show a significant progression-free survival benefit with peri-operative chemotherapy on an intention to treat basis, an improvement in progressionfree survival of $9.2 \%$ at 3 years was seen in those patients who achieved surgical resection. An additional noteworthy finding in this study was an increase in the post-operative complication rate in patients who received peri-operative chemotherapy at 25 vs $16 \%$ in the surgery-alone arm (Nordlinger et al, 2008). Data suggest that the choice of chemotherapeutic agents (Vauthey et al, 2006), length of pre-operative therapy (Aloia et al, 2006; Karoui et al, 2006) and interval between chemotherapy and surgery (Welsh et al, 2007) may all influence the associated surgical morbidity. The relatively short interval between chemotherapy and surgery in the EORTC study (median 4.1 weeks) may have contributed to the excess surgical complication rate seen.

Together with enabling cytoreduction, a further advantage of pre-operative chemotherapy is in allowing for an assessment of chemosensitivity, a marker of underlying disease biology (Charnsangavej et al, 2006). Progression on chemotherapy is an indicator of poor outcome following hepatic resection (Adam et al, 2004b) and may be used to aid the selection of appropriate surgical candidates. In our study, the length of pre-operative chemotherapy used in subgroup B was relatively short, with a median number of four pre-operative treatment cycles. This is a shorter period of pre-operative treatment than that used in other studies evaluating conversion therapy (Bismuth et al, 1996; Alberts et al, 2005; Masi et al, 2006) in which the duration of chemotherapy was typically 6 months. Our treatment policy of early resection may have contributed to the relatively high rate of early post-operative failure seen in subgroup B. In this high-risk group, a more prolonged period of chemotherapy may have aided the selection of a better prognosis patient group for resection by the exclusion of those who progress while receiving chemotherapy.

Advances in surgery have significantly influenced this field of practice with the criteria for disease resection becoming increasingly broad (Poston et al, 2006; Nordlinger et al, 2007; Pawlik et al, 2008). Consequently it is now possible to undertake liver resection in a greater proportion of patients with adverse disease features who are at higher risk of early post-operative failure. A variety of clinical prognostic scoring systems have been proposed (Fong et al, 1999; Iwatsuki et al, 1999; Adam et al, 2004a; Malik et al, 2007; Arru et al, 2008; Kattan et al, 2008) to aid the identification of patients at higher risk for disease recurrence and allow treatment to be tailored accordingly. It is envisaged that advances in molecular medicine will further identify reliable markers of disease biology, thus enhancing our ability to predict both patient outcome and individual treatment response (Charnsangavej et al, 2006; Neal et al, 2006; Pawlik and Choti, 2007; Amado et al, 2008). The availability of robust methods to assess disease biology will further enable a personalised approach to therapy, allowing the rational application of both surgery and chemotherapy in an individual patient and minimising the exposure to morbid inventions.

\section{CONCLUSION}

The results of this prospective study illustrate the wide variation in patient outcome according to baseline liver resectability status and highlight the potential value a revised staging system may have in clinical practice.

\section{ACKNOWLEDGEMENTS}

Supported by Royal Marsden Hospital National Health Service (NHS) Foundation Trust. We acknowledge NHS funding to the NIHR Biomedical Research Centre. This article was written by D Watkins, D Cunningham and I Chau; patient recruitment was carried out by D Cunningham, SS Mudan and N Karanjia; data collection was carried out by A Gillbanks; data analysis was conducted by A Norman and S Ashley and the final approval by all authors.

\section{Conflict of interest}

David Cunningham: Consultant or Advisory Role in Hoffmann-La Roche \& Sanofi Aventis, Honoraria from Hoffmann-La Roche \& Sanofi Aventis, Research Funding from Hoffmann-La Roche \& Sanofi Aventis, Expert Testimony in Hoffmann-La Roche; Ian Chau: Consultant or Advisory Role in Hoffmann_La Roche, Honoraria from Hoffmann-La Roche; D Watkins, S Ashley, SS Mudan, G Brown, N Karanjia, AR Norman, A Gillbanks: There is no conflicts of interest to report.

Supplementary Information accompanies the paper on British Journal of Cancer website (http://www.nature.com/bjc)

\section{REFERENCES}

Adam R, Delvart V, Pascal G, Valeanu A, Castaing D, Azoulay D, Giacchetti S, Paule B, Kunstlinger F, Ghemard O, Levi F, Bismuth H (2004a) Rescue surgery for unresectable colorectal liver metastases downstaged by chemotherapy: a model to predict long-term survival. Ann Surg 240: 644-657; discussion $657-8$

Adam R, Pascal G, Castaing D, Azoulay D, Delvart V, Paule B, Levi F, Bismuth H (2004b) Tumor progression while on chemotherapy: a contraindication to liver resection for multiple colorectal metastases? Ann Surg 240: 1052 -1061; discussion 1061 -4

Alberts SR, Horvath WL, Sternfeld WC, Goldberg RM, Mahoney MR, Dakhil SR, Levitt R, Rowland K, Nair S, Sargent DJ, Donohue JH (2005) Oxaliplatin, fluorouracil, and leucovorin for patients with unresectable liver-only metastases from colorectal cancer: a North Central Cancer Treatment Group phase II study. J Clin Oncol 23: 9243-9249

Aloia T, Sebagh M, Plasse M, Karam V, Levi F, Giacchetti S, Azoulay D, Bismuth H, Castaing D, Adam R (2006) Liver histology and surgical outcomes after preoperative chemotherapy with fluorouracil plus oxaliplatin in colorectal cancer liver metastases. J Clin Oncol 24: 4983-4990

Amado RG, Wolf M, Peeters M, Van Cutsem E, Siena S, Freeman DJ, Juan T, Sikorski R, Suggs S, Radinsky R, Patterson SD, Chang DD (2008) Wild-type KRAS is required for panitumumab efficacy in patients with metastatic colorectal cancer. J Clin Oncol 26: 1626-1634
Arru M, Aldrighetti L, Castoldi R, Di Palo S, Orsenigo E, Stella M, Pulitano C, Gavazzi F, Ferla G, Di Carlo V, Staudacher C (2008) Analysis of prognostic factors influencing long-term survival after hepatic resection for metastatic colorectal cancer. World J Surg 32: 93-103

Bismuth H, Adam R, Levi F, Farabos C, Waechter F, Castaing D, Majno P, Engerran L (1996) Resection of nonresectable liver metastases from colorectal cancer after neoadjuvant chemotherapy. Ann Surg 224: 509-520; discussion 520-2

Borner MM, Dietrich D, Stupp R, Morant R, Honegger H, Wernli M, Herrmann R, Pestalozzi BC, Saletti P, Hanselmann S, Muller S, Brauchli P, Castiglione-Gertsch M, Goldhirsch A, Roth AD (2002) Phase II study of capecitabine and oxaliplatin in first- and second-line treatment of advanced or metastatic colorectal cancer. J Clin Oncol 20: $1759-1766$

Cassidy J, Clarke S, Diaz-Rubio E, Scheithauer W, Figer A, Wong R, Koski S, Lichinitser M, Yang TS, Rivera F, Couture F, Sirzen F, Saltz L (2008) Randomized phase III study of capecitabine plus oxaliplatin compared with fluorouracil/folinic acid plus oxaliplatin as first-line therapy for metastatic colorectal cancer. J Clin Oncol 26: 2006-2012

Charnsangavej C, Clary B, Fong Y, Grothey A, Pawlik TM, Choti MA (2006) Selection of patients for resection of hepatic colorectal metastases: expert consensus statement. Ann Surg Oncol 13: 1261 - 1268 
de Gramont A, Figer A, Seymour M, Homerin M, Hmissi A, Cassidy J, Boni C, Cortes-Funes H, Cervantes A, Freyer G, Papamichael D, Le Bail N, Louvet C, Hendler D, de Braud F, Wilson C, Morvan F, Bonetti A (2000) Leucovorin and fluorouracil with or without oxaliplatin as first-line treatment in advanced colorectal cancer. J Clin Oncol 18: 2938-2947

Douillard JY, Cunningham D, Roth AD, Navarro M, James RD, Karasek P, Jandik P, Iveson T, Carmichael J, Alakl M, Gruia G, Awad L, Rougier P (2000) Irinotecan combined with fluorouracil compared with fluorouracil alone as first-line treatment for metastatic colorectal cancer: a multicentre randomised trial. Lancet 355: 1041 - 1047

Fong Y, Fortner J, Sun RL, Brennan MF, Blumgart LH (1999) Clinical score for predicting recurrence after hepatic resection for metastatic colorectal cancer: analysis of 1001 consecutive cases. Ann Surg 230: 309-318; discussion 318-21

Goldberg RM, Sargent DJ, Morton RF, Fuchs CS, Ramanathan RK, Williamson SK, Findlay BP, Pitot HC, Alberts SR (2004) A randomized controlled trial of fluorouracil plus leucovorin, irinotecan, and oxaliplatin combinations in patients with previously untreated metastatic colorectal cancer. J Clin Oncol 22: 23-30

Greene FL, Page DL, Fleming ID, Fritz A, Balch CM, Haller DM, Morrow M (2002) AJCC Cancer Staging Manual, 6th edn, Springer Verlag: New York

Grothey A, Sugrue M, Hedrick E, Purdie D, Yi J, Dong W, Kozloff M, the BRiTE Study Investigators (2007) Association between exposure to bevacizumab (BV) beyond first progression (BBP) and overall survival (OS) in patients (pts) with metastatic colorectal cancer (mCRC): Results from a large observational study (BRiTE). J Clin Oncol (Meeting Abstracts) 25: 4036

Hurwitz H, Fehrenbacher L, Novotny W, Cartwright T, Hainsworth J, Heim W, Berlin J, Baron A, Griffing S, Holmgren E, Ferrara N, Fyfe G, Rogers B, Ross R, Kabbinavar F (2004) Bevacizumab plus irinotecan, fluorouracil, and leucovorin for metastatic colorectal cancer. $N$ Engl J Med 350: 2335-2342

Iwatsuki S, Dvorchik I, Madariaga JR, Marsh JW, Dodson F, Bonham AC, Geller DA, Gayowski TJ, Fung JJ, Starzl TE (1999) Hepatic resection for metastatic colorectal adenocarcinoma: a proposal of a prognostic scoring system. J Am Coll Surg 189: 291 - 299

Jonker DJ, O'Callaghan CJ, Karapetis CS, Zalcberg JR, Tu D, Au HJ, Berry SR, Krahn M, Price T, Simes RJ, Tebbutt NC, van Hazel G, Wierzbicki R, Langer C, Moore MJ (2007) Cetuximab for the treatment of colorectal cancer. N Engl J Med 357: 2040 - 2048

Kaplan E, Meier P (1958) Nonparametric estimation from incomplete observations. J Am Stat Assoc 53: 457-481

Karoui M, Penna C, Amin-Hashem M, Mitry E, Benoist S, Franc B, Rougier P, Nordlinger B (2006) Influence of preoperative chemotherapy on the risk of major hepatectomy for colorectal liver metastases. Ann Surg 243: $1-7$

Kattan MW, Gonen M, Jarnagin WR, DeMatteo R, D’Angelica M, Weiser M, Blumgart LH, Fong Y (2008) A nomogram for predicting disease-specific survival after hepatic resection for metastatic colorectal cancer. Ann Surg 247: $282-287$

Khatri VP, Chee KG, Petrelli NJ (2007) Modern multimodality approach to hepatic colorectal metastases: solutions and controversies. Surg Oncol 16: $71-83$

Malik HZ, Prasad KR, Halazun KJ, Aldoori A, Al-Mukhtar A, Gomez D, Lodge JP, Toogood GJ (2007) Preoperative prognostic score for predicting survival after hepatic resection for colorectal liver metastases. Ann Surg 246: $806-814$

Masi G, Cupini S, Marcucci L, Cerri E, Loupakis F, Allegrini G, Brunetti IM, Pfanner E, Viti M, Goletti O, Filipponi F, Falcone A (2006) Treatment with 5-fluorouracil/folinic acid, oxaliplatin, and irinotecan enables surgical resection of metastases in patients with initially unresectable metastatic colorectal cancer. Ann Surg Oncol 13: 58-65

Nagashima I, Takada T, Nagawa H, Muto T, Okinaga K (2006) Proposal of a new and simple staging system of colorectal liver metastasis. World J Gastroenterol 12: 6961 - 6965

Neal CP, Garcea G, Doucas H, Manson MM, Sutton CD, Dennison AR, Berry DP (2006) Molecular prognostic markers in resectable colorectal liver metastases: a systematic review. Eur J Cancer 42: 1728-1743

NICE (2002) Irinotecan, oxaliplatin and raltitrexed for advanced colorectal cancer (no.33). Natl Inst Clin Excellence

Nordlinger B, Sorbye H, Glimelius B, Poston GJ, Schlag PM, Rougier P, Bechstein WO, Primrose JN, Walpole ET, Finch-Jones M, Jaeck D, Mirza D, Parks RW, Collette L, Praet M, Bethe U, Van Cutsem E, Scheithauer W, Gruenberger T (2008) Perioperative chemotherapy with FOLFOX4 and surgery versus surgery alone for resectable liver metastases from colorectal cancer (EORTC Intergroup trial 40983): a randomised controlled trial. Lancet 371: 1007-1016

Nordlinger B, Van Cutsem E, Rougier P, Köhne C-H, Ychou M, Sobrero A, Adam R, Arvidsson D, Carrato A, Georgoulias V, Giuliante F, Glimelius B, Golling M, Gruenberger T, Tabernero J, Wasan H, Poston G (2007) Does chemotherapy prior to liver resection increase the potential for cure in patients with metastatic colorectal cancer? A report from the European Colorectal Metastases Treatment Group. Euro J Cancer 43: 2037-2045

Pawlik TM, Choti MA (2007) Shifting from clinical to biologic indicators of prognosis after resection of hepatic colorectal metastases. Curr Oncol Rep 9: $193-201$

Pawlik TM, Schulick RD, Choti MA (2008) Expanding criteria for resectability of colorectal liver metastases. Oncologist 13: 51-64

Poston G, Adam R, Vauthey JN (2006) Downstaging or downsizing: time for a new staging system in advanced colorectal cancer? J Clin Oncol 24: $2702-2706$

Poston GJ, Figueras J, Giuliante F, Nuzzo G, Sobrero AF, Gigot JF, Nordlinger B, Adam R, Gruenberger T, Choti MA, Bilchik AJ, Van Cutsem EJ, Chiang JM, D'Angelica MI (2008) Urgent need for a new staging system in advanced colorectal cancer. J Clin Oncol 26: 4828-4833

Rees M, Tekkis PP, Welsh FK, O'Rourke T, John TG (2008) Evaluation of long-term survival after hepatic resection for metastatic colorectal cancer: a multifactorial model of 929 patients. Ann Surg 247: 125-135

Rothenberg ML, Cox JV, Butts C, Navarro M, Bang YJ, Goel R, Gollins S, Siu LL, Laguerre S, Cunningham D (2008) Capecitabine plus oxaliplatin (XELOX) versus 5-fluorouracil/folinic acid plus oxaliplatin (FOLFOX-4) as second-line therapy in metastatic colorectal cancer: a randomized phase III noninferiority study. Ann Oncol

Sato T, Konishi K, Yabushita K, Nojima N, Kimura H, Maeda K, Tsuji M, Miwa A (1998) The time interval between primary colorectal carcinoma resection to occurrence of liver metastases is the most important factor for hepatic resection. Analysis of total course following primary resection of colorectal cancer. Int Surg 83: 340-342

Schlag P, Hohenberger P, Herfarth C (1990) Resection of liver metastases in colorectal cancer-competitive analysis of treatment results in synchronous versus metachronous metastases. Eur J Surg Oncol 16: 360-365

Simon R (1989) Optimal two-stage designs for phase II clinical trials. Control Clin Trials 10: $1-10$

Souglakos J, Androulakis N, Syrigos K, Polyzos A, Ziras N, Athanasiadis A, Kakolyris S, Tsousis S, Kouroussis C, Vamvakas L, Kalykaki A, Samonis G, Mavroudis D, Georgoulias V (2006) FOLFOXIRI (folinic acid, 5-fluorouracil, oxaliplatin and irinotecan) vs FOLFIRI (folinic acid, 5-fluorouracil and irinotecan) as first-line treatment in metastatic colorectal cancer (MCC): a multicentre randomised phase III trial from the Hellenic Oncology Research Group (HORG). Br J Cancer 94: 798 - 805

Therasse P, Arbuck SG, Eisenhauer EA, Wanders J, Kaplan RS, Rubinstein L, Verweij J, Van Glabbeke M, van Oosterom AT, Christian MC, Gwyther SG (2000) New guidelines to evaluate the response to treatment in solid tumors. European Organization for Research and Treatment of Cancer, National Cancer Institute of the United States, National Cancer Institute of Canada. J Natl Cancer Inst 92: 205-216

Tournigand C, Andre T, Achille E, Lledo G, Flesh M, Mery-Mignard D, Quinaux E, Couteau C, Buyse M, Ganem G, Landi B, Colin P, Louvet C, de Gramont A (2004) FOLFIRI followed by FOLFOX6 or the reverse sequence in advanced colorectal cancer: a randomized GERCOR study. I Clin Oncol 22: 229-237

Tsai MS, Su YH, Ho MC, Liang JT, Chen TP, Lai HS, Lee PH (2007) Clinicopathological features and prognosis in resectable synchronous and metachronous colorectal liver metastasis. Ann Surg Oncol 14: $786-794$

Van Cutsem E, Peeters M, Siena S, Humblet Y, Hendlisz A, Neyns B, Canon JL, Van Laethem JL, Maurel J, Richardson G, Wolf M, Amado RG (2007) Open-label phase III trial of panitumumab plus best supportive care compared with best supportive care alone in patients with chemotherapy-refractory metastatic colorectal cancer. J Clin Oncol 25: $1658-1664$

Vauthey JN, Pawlik TM, Ribero D, Wu TT, Zorzi D, Hoff PM, Xiong HQ, Eng C, Lauwers GY, Mino-Kenudson M, Risio M, Muratore A, Capussotti L, Curley SA, Abdalla EK (2006) Chemotherapy regimen predicts steatohepatitis and an increase in 90-day mortality after surgery for hepatic colorectal metastases. J Clin Oncol 24: 2065-2072

Welsh FK, Tilney HS, Tekkis PP, John TG, Rees M (2007) Safe liver resection following chemotherapy for colorectal metastases is a matter of timing. Br J Cancer 96: $1037-1042$ 